\title{
Data-Focused Approach: Developing A New Intervention Method in Applied Psychology
}

\author{
Johana E. Prawitasari ${ }^{1}$, Tiara R. Widiastuti², Walida Asitasari ${ }^{3}$ \\ ${ }^{1}$ Faculty of Psychology, Universitas Kristen Krida Wacana (UKRIDA) \\ ${ }^{2}$ Faculty of Psychology, Universitas Padjadjaran (UNPAD) \\ ${ }^{3}$ Faculty of Ushuluddin, Adab, and Dakwah, IAIN Ponorogo
}

\begin{abstract}
This study aimed to compare the newly developed psychological intervention method by the first author, named data-focused approach, to the more classical processoriented approaches, i.e., gestalt, psychodynamics, and interactional group psychotherapies. A pretest-posttest design was used. Twenty-one participants were assigned into four experimental groups. Measures used were self-regulation, emotional awareness, and meta-emotion scales as well as stated agenda on interpersonal relationships. They were administered before and after therapy sessions. Results indicated that the new method was evidently compatible with the classical psychotherapy approaches. Specifically, participants in the data-focused approach were satisfied with the aiming of behavioral change in their interpersonal relationships. The new approach is effective to be applied in group processes. Thus, this new method is also recommended to be studied in other settings. Using the simplified procedure, it is hoped that other professionals, like medical doctors, nurses, midwifes, women activists in public health centers may use it to provide better service for the community.
\end{abstract}

Keywords: data-focused approach; group processes; group psychotherapy

Inventing psychotherapy in Indonesia requires practice and courage to define and construct the approach. The principal investigator (PI) has experience in practicing psychotherapy with real clients as well as teaching various modalities of intervention to graduate students. Thus far, the pure psychodynamic approach needs a longer period of therapy sessions. It takes years for a classical psychotherapist to facilitate clients in revisiting her/his life pattern, modifying it, and growing to be a more adaptive individual. Moreover, achieving the outcome of psychotherapy in which the clients feel pleased with her/himself as they may live their lives full of

\footnotetext{
1 Address for corespondence:
}

jeprawitasari@ukrida.ac.id contentment is inevitable. Empirically, it had been found that short term psychodynamic therapy was effective for psychiatric cases such as anxiety, depression, personality and mixed disorders (Johansson, Town, \& Abbass, 2014; Lilliengren, Johansson, Lindqvist, Mechler, \& Andersson, 2016; Town, Abbass, \& Bernier, 2013).

Based on personal experiences of the PI's in doing therapy with several clients, the psychodynamic therapy sessions can be shortened using a technique that was previously named "facts and inferences" relational psychotherapy. The term, however, sounds too clinical and too technical. It is then, changed into the "data-focused" approach. The new approach might be suitable to be simplified and transferred to other settings, such as organizations, and 
public health centers, in addition to individual psychotherapy for clinical cases. The new term will sound more objective instead of too clinical.

The new method is based on the short-term dynamic psychotherapy in which participants of the group processes identify what their fantasy is and what the fact is that they have narrated at the beginning of therapy sessions. They may see the differences between what they think and feel about themselves and the data that they presented in front of other participants during group processes. The leader of the group and other group members then subtly confront the gap between fantasy and data presented by the person who is working on the agenda of his/her interpersonal relationship.

Increasing awareness of the cultural effect on psychotherapy process yields question related to the effectiveness of generic psychotherapy approaches in different cultural contexts. Previous research on the field indicated that proper technical modification is needed to address the issue. This technical modification covers not only the communication process and therapeutic focus but also modification in therapeutic model (Tseng, 2004). Besides influencing the suitable therapeutic model, culture also influences clients' expectations for psychotherapy and therapist (Donnelly, 1992). Therefore, developing this new method is an effort to support indigenous approach in psychotherapy based on the characteristics of the clients in Indonesia, who are usually expecting a suitable, comfortable, yet short term cure for their relational problems.

One indicator in psychotherapy is that during its processes, participants are usually focusing on their corrective emotional experience because emotion is the core of humanity that affects people's relationships with others (Yalom, 1985). Compared to other mammals that may survive alone, human being will not be able to survive without another human being to take care of them since infancy. Emotion, then, is a special human capacity in expressing what they feel inside as well as reactions toward others and the external world. Greenberg \& Pascual-Leon (2006) reviewed various approaches in psychotherapy and found that emotion processing expressed during the sessions showed favorable outcome. They found that four types of emotion processing, namely emotion awareness and arousal, emotion regulation, emotion transformation, and active reflection on emotion, were processed during psychotherapy and resulting in effective outcome. Specifically, when the therapists were also engaged during the emotions processing, the psychotherapy outcome was more effective.

During psychotherapy processes, in which the event is emotion loaded, emotion awareness was found as a key indicator to result in change of clients' narration about themselves (Greenberg \& Pascual-Leone, 2006). Emotion awareness is a form of adaptive emotion regulation. It means being aware to monitor and differentiate various emotions and to identify its causes (Rieffe, Oosterveld, Miers, Meerum Terwogt, \& Ly, 2008). Emotion awareness covers individual's attitude toward emotional experience whether it is positive or negative, or it is coming from within or outside the self. Although other studies showed different results, in general, emotion awareness is defined as skills to identify emotions and to describe emotion experienced by self and others (Lane, Sechrest, Riedel, Shapiro, \& Kaszniak, 2000; Thompson, Dizén, \& Berenbaum, 2009). 
In social relationships, emotion awareness and emotional competency in general are important in sustaining the relational issue itself (Brackett, Mayer, \& Warner, 2004; Brackett, Rivers, Shiffman, Lerner, \& Salovey, 2006; Gupta \& Kumar, 2010). Emotion awareness in social context is defined as ability to identify and describe self and others' emotions (Thompson et al., 2009). There are five levels of the experience. First is bodily sensation. Second is a tendency to act. Third is experiencing single emotion in one episode. Fourth is experiencing several emotions in one episode. Fifth is a combination of several emotions in one period.

People with low emotion awareness could not identify what they feel at the moment, but they may evaluate the emotion as good or bad. People with high emotion awareness will be able to identify and skillfully describe the complexity of what they feel inside as well as the trigger of the expressions from external world. In intimate relationship between couples, emotion awareness will be perceived as supporting their satisfaction in their relationship (Croyle \& Waltz, 2002). Among Taiwanese, emotion awareness was found to be correlated positively with display rules of emotions in the working place. Emotion awareness, then, is important to how people adapt to the culture of work place because it plays role in bridging the emotions felt and the appropriate emotions to display or not to display in social contexts (Chen, Ku, Shyr, Chen, \& Chou, 2009).

Other than emotion awareness, metaemotions also become a focus during psychotherapy sessions. Meta-emotions affect willingness to express and process certain emotions as well as affecting one's involvement on their emotional processing
(Lavee \& Ben-Ari, 2004). Meta-emotion Philosophy (MEP) or the shortened version of meta-emotion, is a description of feelings and thoughts about emotion, specifically emotion experienced by an individual in certain situation. Metaemotion is defined as thought, reaction, and feeling of an emotion (Hunter et al., 2011; Mitmansgruber, Beck, \& Schüßler, 2008). Thinking and feeling toward an emotion could become a tendency to consider and feel whether an emotion is positive or negative (Bartsch, Mangold, Viehoff, \& Vorderer, 2006).

Psychotherapy can be seen as a learning process (Corsini \& Wedding, 2008). Through the process, clients learn how to react differently and more adaptively. Thus, clients' involvement in the process becomes central, because basically therapy requires alliance between the therapist and the client. Self-regulated learning, a process of deciding the aim for self and a behavioral process to achieve the aim (Doll, 2010; Ormrod, 2006), is reflected during therapy process. Ormrod (2006) explained that self-regulated learning consists of three steps: 1) before responding there must be a standard in achieving the self-aim; 2) during responding there must be self-instruction and self-monitoring; 3) after responding there are self-evaluation and self-praising. Self-reflection as part of self-regulation (Barnard-Brak, Lan, \& Paton, 2010) is very important in self-evaluation during the group processes since it facilitates corrective emotional experience as the outcome of any psychotherapy.

The background of this study is based on personal experience in handling clients in the PI's private practice. Therefore, there is no previous formal study indicating specific results, except that this study is based on her experiences in 
therapy sessions. Based on her intensive observations during individual therapy with real clients, this new method is quicker in obtaining self-awareness of the client's core conflict than the classical approach like Gestalt, Psychodynamic, and Interactional group approaches that have been used in her practice. The PI has experiences in applying those three classical approaches with real clients, graduate students, and any participant in the group processes. Results of those three classical approaches are satisfying for the participants in the group processes.

When the new method is applied for individual case, the result of therapy is satisfying in obtaining self-awareness on the conflicting relational cases. The question is when it is to be applied in the group processes, is the result would be satisfying for the participants? The group processes give an opportunity to the participants to learn from one another and thus making improvement in their interpersonal relationships (Erskine, 2010). Since all subjects in the study were volunteers and therefore were wellfunctioning people with no significant psychopathology, it was presumed that they had average emotion awareness, meta-emotion, and self-regulated learning in their everyday life. Participating in the group processes, they were facilitated to learn how to improve their emotion awareness, meta-emotion, and self-regulation in their relationship with others. They learned from each other, regardless the approach we used, to improve their interpersonal relationship using emotion awareness, meta-emotion, and self-regulation as indicators of improvements during the group processes.

The purpose of this study was to provide an evidence that the "datafocused approach" is compatible to the more classical process-oriented psychotherapy approaches, i.e. gestalt, psychodynamic, and interactional group processes. The question was whether the new approach will facilitate the growth of the participants in their emotion awareness, meta-emotions, as well as selfregulation in learning about self in relation to others when applied in the group format. If this approach is proven to be more or at least equally effective for clients in gaining insight in relatively short period of time, then it can be simplified and transferred to other disciplines and practiced by lay-people to be used in a

Pre-test

Post-test

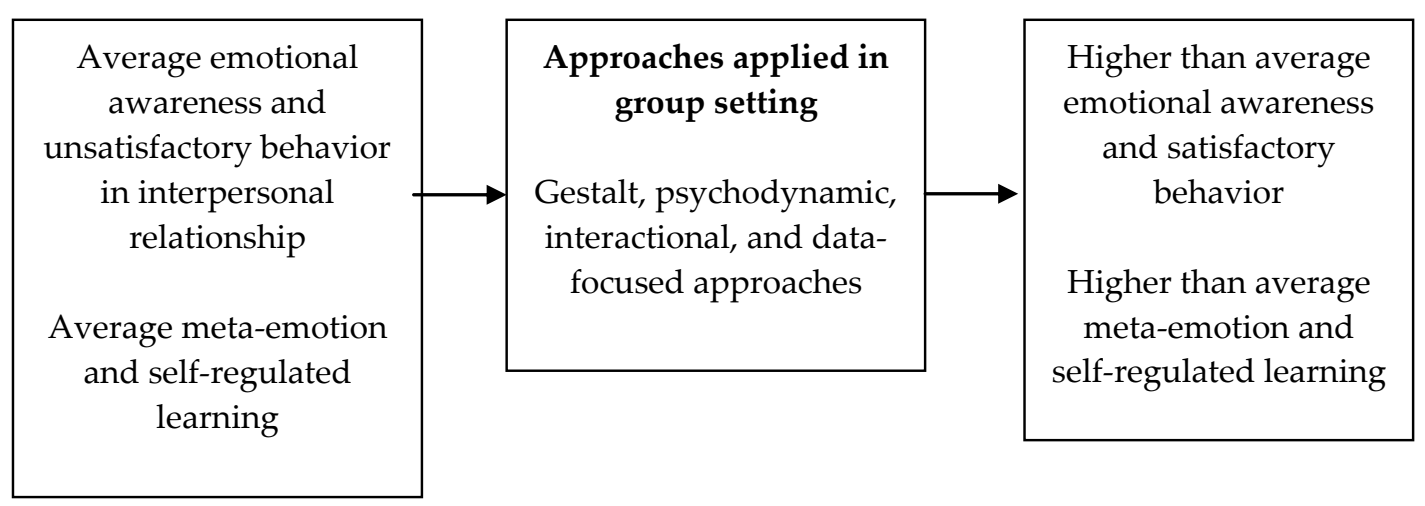

Figure 1. Conceptual framework 
macro setting of clinical psychology (Prawitasari, 2011). This neutral term of the new approach is also transferrable for other settings such as community, medical facility, organization, public health center, and school in the long run after this study is upscaled. Even though the number of targeted participants in the experiment was limited, the observations were extensive. This will convince other disciplines that the approach is effective and worthwhile to be tried out in larger settings.

The hypothesis in this study was that the data-focus approach, specifically in the interpersonal relation uneasiness, is compatible with Gestalt, Psychodynamic, and Interactional approaches, in improving emotion awareness, metaemotion, and self-regulation and stated agenda during the group processes. The working hypothesis in this study then, that there were no differences in emotion awareness, meta-emotion, self-regulation, and stated agenda in all groups after the therapy ended. All participants in all groups showed improvement in emotion awareness, meta-emotion, self-regulation, and stated agenda in their relationship with others as reported by themselves, and as shown in the observed behavior during the group processes. The improvement after the therapy ended was to be inferred from the gain score obtained on each objective measure, and stated personal stated agenda in all groups.

\section{Method}

Research design used in this study was pretest-posttest design (Christensen, 2007). Participants were randomly assigned to one of the groups. All measures were administered before the group therapy started and after the therapy ended.
Another follow-up measurement in three months was added to check the sustainable effect of the therapy sessions.

Subjects of this study were mostly volunteering undergraduate and graduate students and two junior faculty members, who were interested in relational therapy. Twenty-one participants who experienced relational problems were involved in this study. Convenient sampling (Shaughnessy, Zechmeister, \& Zechmeister, 2011) was implemented so that subjects were selected primarily based on their availability and willingness to participate. They chose the date, but they did not know about the modality being used on that date. We provided monetary compensation for their time as volunteer clients in this study. Their real agenda on interpersonal relationship was to be set in the beginning of the session before group process started. They worked on their committed agendas during the group process and eventually they would reach satisfactory output after the therapy was completed. They were genuine in presenting themselves in the group processes. There were unequal number of participants for each group. Four subjects were assigned into Data-focused Group (DG), seven in Gestalt Therapy Group (GG), five in Psychodynamic Group (PG), and five in Interactional Group (IG).

Independent variable in this study was group processes in each approach. There were four group psychological interventions studied in this research. They were Gestalt, Psychodynamic, Interactional, and Data-Focused approaches. Dependent variables in this study were emotion awareness, metaemotion, self-regulation learning processes, and self-appointed behavioral change related to interpersonal relational problems. 
Objective measures used in this study were emotion awareness (Lane \& Schwartz, 1987), meta-emotion (Mitmansgruber, Beck, Höfer, \& Schüßler, 2009; Mitmansgruber et al., 2008), selfregulation scales (Barnard-Brak et al., 2010). Those objective measures were developed by the research team based on previous studies done by the authors in the references. Participants were also asked to indicate the behavioral change agenda in the beginning and in the end of the group processes as subjective measure of the group processes.

Research procedure. The PI announced in her undergraduate and graduate classes about the experiment. The research team also announced the experiment by posting the volunteering invitation in the faculty public spaces. The announcement included how to contact the research team if there were students interested to participate in the experiment. The expected number of volunteers were 7-12 participants for each group and the total number expected were 28-48 participants. In reality, some students who promised to participate did not show up during the day in which the group process for each modality was conducted. This situation affected the total number in each group to become unequal.

All interested participants were asked to sign the the subject informed consent as part of the experiment with all the rights, risks if any, and consequences when joining the research activities. There were no major side effects expected in participating the experiment. In the inform consent, it was stated that if there were any side effect, the PI as a senior clinical psychologist experienced in handling emergency case, would take care of the participants who were in needs of special treatment as a result of the experiment.
Participants were assigned to Gestalt, Psychodynamic, Interactional, and Datafocused approaches.

The PI was in charge of leading the group using those approaches. The research team observed the group processes in all four approaches using dependent variables measures. The group processes were videotaped. These documents were to be observed outside of therapy sessions to see the reliability of the observations. Pre and post measures on the dependent variables were performed. Group processes were run in one day simultaneously in order to shorten the time. The group process started at 9:00 and ended at 17:00. There were breaks for tea and coffee in the morning and afternoon. Lunch were provided. There were 6 effective hours of treatment time duration.

Data analysis used pre-and-post and three months follow up comparisons on emotion awareness, meta-emotion, selfregulation measures, and self-stated personal agenda on behavioral change in interpersonal relationships. The gain score on each measure in each group was presented through visual inspection using time-series graphs. Analysis of variance (ANOVA) to test the statistical difference between the classical approaches and the newly invented method was also used.

\section{Result}

Results were presented in graphs on the pre and post measures in all dependent variables, i.e. emotion awareness, metaemotions, self-regulation learning, selfappointed agenda on perception and behavioral change related to interpersonal relationship. Specifically, participants in all groups stated their agendas on behavioral change related to their relationships with significant others. 
Figure 2 showed that data-focused approach was not as compatible with Gestalt and Interactional approaches to improve interpersonal relation perceived by participants. Short term Psychodynamic also looked less promising compared to those two modalities. The participants in these two approaches perceived that their interpersonal relation almost remained the same before and after therapy sessions. Data-focused approach showed decline on perceived interpersonal relationship in the follow up period. Volunteer clients in psychodynamic approach showed a little improvement during follow-up period. From visual inspection in Figure 2, it was obvious that interactional group, and Gestalt psychotherapy looked more promising in changing interpersonal relationship perceived by the participants.

Figure 3 showed that the most promising approaches in facilitating emotion awareness were interactional group therapy and data-focused approaches. Psychodynamic and Gestalt therapies looked less promising since the gain scores were less than the other groups. It must be borne in mind though that the psychodynamic and Gestalt participants had higher emotion awareness and gained less on that measure than the other two that the participants had less emotion awareness in the beginning and gained much more at the end of therapy processes.

Data in Figure 4 was inconclusive. Three groups showed incline graphs on meta-emotions pre and post therapy sessions. One group showed decline during the post measure in positive metaemotion of the participants'. Almost all participants showed decline in their positive meta-emotions during the follow up period. Perceived forethought during the therapy process in all four modalities showed no obvious differences. Only participants in psychodynamic group therapy showed decline on their perceived forethought during the follow up period.

Figure 5 showed that the most promising approaches to facilitate selfregulation learning during therapy sessions were Gestalt and psychodynamic psychotherapies, specifically on performance control measure. Interactional group psychotherapy and data-focused approach showed less gain in the participants' perception toward selfregulation learning. Participants in the last two approaches had higher scores than the first two. From the visual inspection in Figure 5 it could be observed that the graphs showed the obvious difference in the participants' gain scores on the measure.

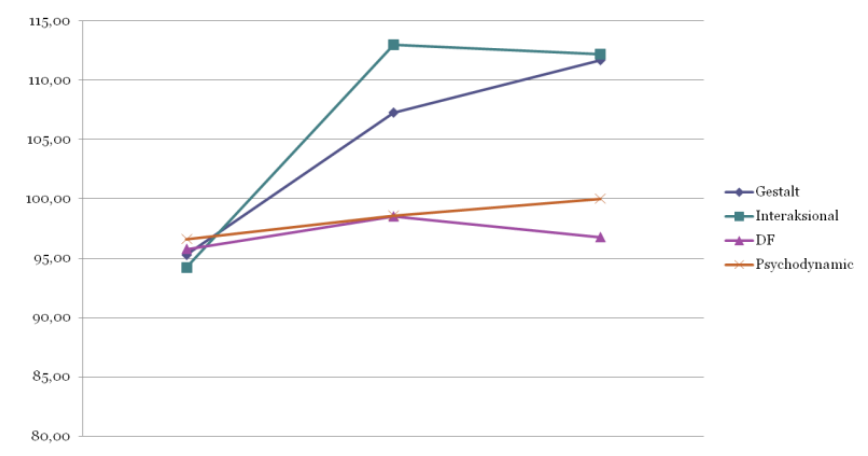

Figure 2. Progress of perceived interpersonal relationship during therapy sessions 


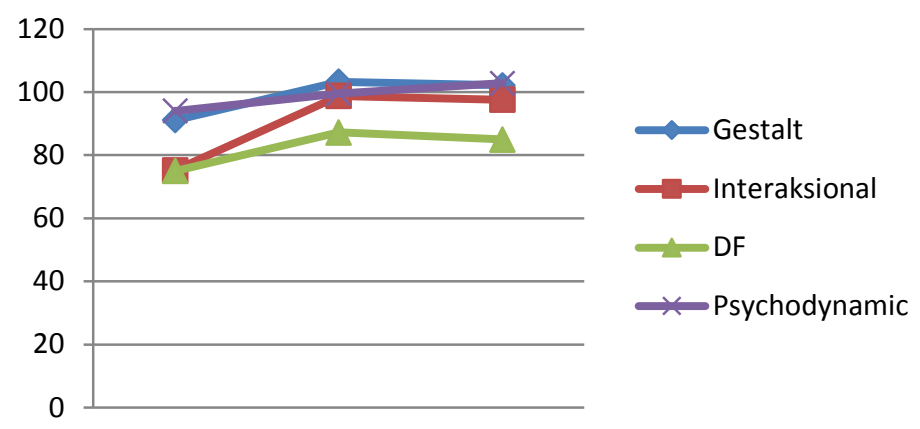

Figure 3. Progress of emotion awareness during therapy sessions.

(a)

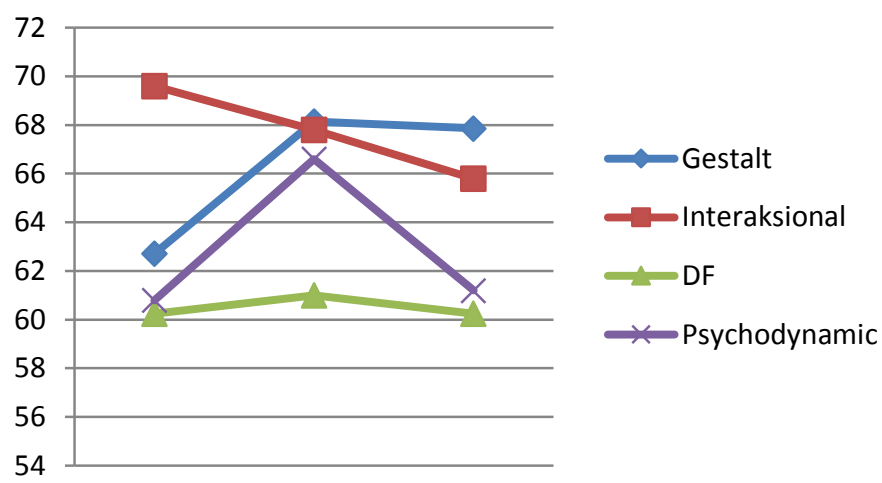

(b)

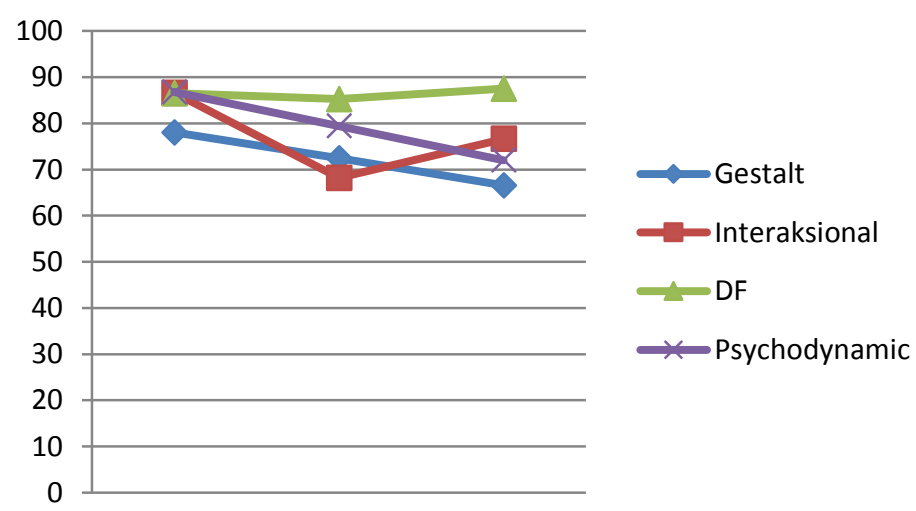

Figure 4. Changing in positive meta-emotions (a) and negative meta-emotions (b) during therapy sessions.

It was interesting that on selfreflection, participants in psychodynamic group evaluated the lowest compared to data-focused, Gestalt, and interactional group processes. During the follow up period those participants also showed decline on the self-reflection. The most promising process to support selfreflection by the participants was interactional group therapy. Gestalt and data-focused approaches showed decline in self-reflection during the post test, but then went up clearly. Yet, when we observed Table 1 on ANOVA results, it was obvious that all approaches were in the same level based on the gain score. There were no significant differences among all groups on the objective measures used in this study.

Self-appointed behavioral changes to be achieved during the group sessions in 
all modalities were shown in Figure 6. The data-focused approach showed the highest score on 5 scales scores followed by psychodynamic, Gestalt, and interactional group therapies. This finding was contradictory to the perceived interpersonal relation that the highest scores were in Gestalt followed by Interactional group psychotherapies. Psychodynamic and data-focused approaches were the lowest. The data showed that data-focused approach facilitated the most improvement on self-appointed behavioral change agenda, even though there were no significant differences statistically. As predicted that there were no significant differences among all dependent variables measures in all psychotherapy modalities. This means that data-focused approach was compatible with the classical approaches.

(b)

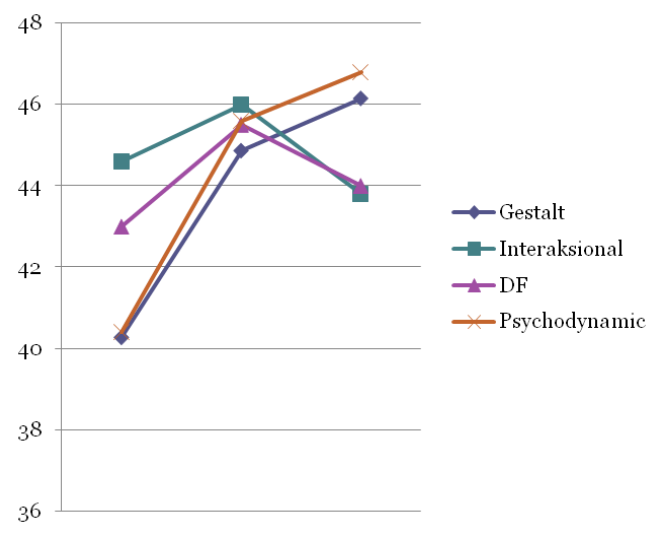

(c)

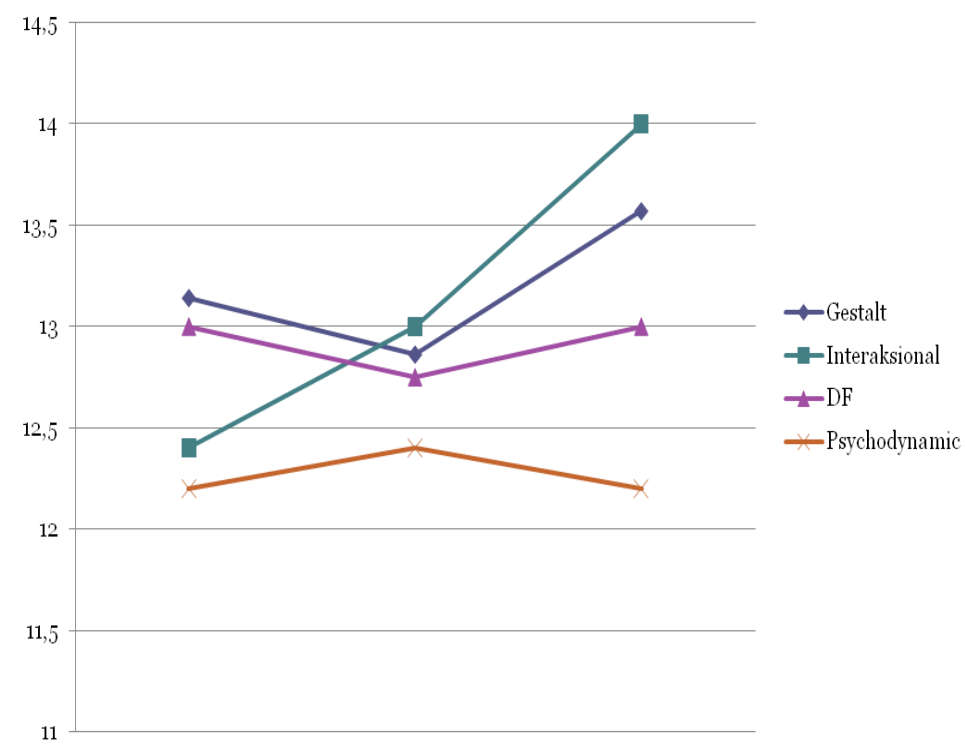

Figure 5. Progress of self-regulation during therapy sessions. Note: $(a)=$ forethought phase, $(b)=$ performance control phase, and (c) = self-reflection phase. 


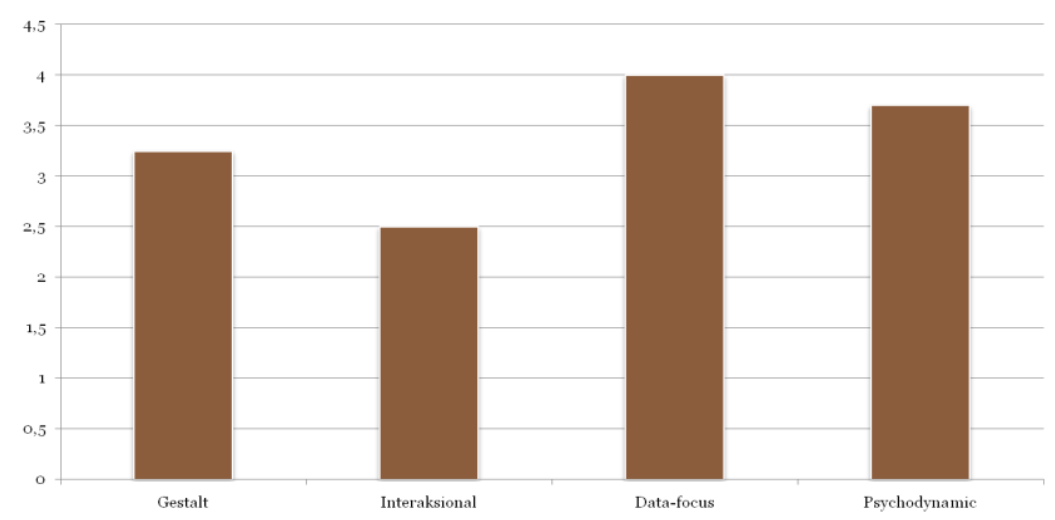

Figure 6. Gain scores based on self-appointed behavioral change agendas across groups.

Table 1.

Differences on Perception Toward Interpersonal Relation, Emotional Awareness, Meta-Emotions, and Self-Regulated Learning in Four Groups

\begin{tabular}{llll}
\multicolumn{1}{c}{ Variable } & \multicolumn{1}{c}{ Time } & F & sig. \\
\hline Perception toward interpersonal relation & Pretest & .772 & .525 \\
& Posttest & .273 & .844 \\
Emotional awareness & Pretest & .730 & .548 \\
Meta-emotions & Posttest & .271 & .846 \\
Positive meta-emotions & & & .099 \\
& Pretest & 2.445 & .255 \\
Negative meta-emotions & Posttest & 1.483 & .556 \\
Self-regulated learning & Pretest & .716 & .270 \\
Forethought phase & Posttest & 1.425 & .324 \\
Performance control phase & & & .625 \\
Self-reflection phase & Pretest & 1.247 & .772 \\
\end{tabular}

All participants showed more than average scores in all objective measures in all groups before the group processes. The gain scores showed improvement after the group process ended. The inference was that all modalities gave chances for the participants to work out on their personal agendas during the group processes, regardless of the approach being used.

\section{Discussion}

This study revealed that the new intervention method proposed was compatible with three classical psychotherapies namely Gestalt, short term Psychodynamic, and Interactional Group. There were no significant differences on emotional awareness, self-regulation, meta-emotion, and self-appointed behavioral change among those four groups during the pretest and post-test periods.

Results of this study indicated that data-focused approach effectively facilitated the group processes almost exactly the same as the other three classical approaches in psychotherapy. This 
inference was based on the gain scores obtained by all participatns in all groups. Although the result is favorable, yet the conclusion must be taken cautiously since the total number in all groups of the participants were only twenty-one.

It must be borne in mind too that various factors are affecting the effectiveness of therapy sessions. One factor is the type of participants. Statistically it must be measured and insured that all participants at least have insignificant scores differences during the pretest. The handicap, however, that all participants were volunteer clients that we did not have the chance to completely randomize in placing them to the four modalities and made it possible that all measures were compatible in all participants before therapy started. Yet, all participants seemed to have more than average scores during the pre-test and higher during the post-test. The result confirmed the working hypothesis proposed in this study.

It is almost impossible to really make the number of participants in each group equal, unless we have plenty volunteer clients signing up for the experiment. If the subject number was large, we could assign waiting list group as a control group. Therefore, the Randomized Control Trials (RCT) could be done properly.

Another obstacle or limitation of this study was that we did not have control as to how the volunteer participants decided for coming or not coming to the day they promised to commit themselves in the group processes. Also, all participants well-functioning individuals without significant psychopathology.

Another factor was the objective measures. The use of emotion awareness, meta-emotion, and self-regulation as objective measures, even though the core working out in psychotherapy is corrective emotional experience, were inconclusive. Each modality affected differently affected those objective measures. Since emotion is experienced in a matter of second, thinking about positive emotion might not be relevant during daily live that almost all participants perceived that positive meta-emotion was of no use so they showed decline in their self-report on the measure. Yet, when participants reported perceived negative meta-emotion before, after, and during follow up periods, participants in the data-focused approach showed almost similar result. Participants in psychodynamic and Gestalt groups showed decline in their negative metaemotions than interactional group participants who showed incline during the follow up period.

The decline and incline trends in the use of positive and negative metaemotions by the participants could be attributed to the fact that emotion itself is very much fluctuating and changing every time depending on the stimuli from within and outside selves. Therefore, metaemotion was not necessarily affected by what modalities to be used. The situation was related to the meta-emotion philosophy (MEP) that it was defined as thinking, reaction, and feeling of an emotion (Hunter et al., 2011). Other researchers also stated that thinking and feelings toward an emotion could become a tendency to opinionate and feel whether an emotion was positive or negative (Bartsch et al., 2006). The current research finding then, was not conclusive in regard to the meaning of meta-emotion in the group processes.

The most promising therapeutic factor is interpersonal relationship (Yalom, 1998). During the group processes participants had learned how to relate to each other and this facilitated perceived change in 
their unsatisfactory relation to the more satisfactory interpersonal relationship. Gestalt therapy, Interactional Group psychotherapy, and Psychodynamic psychotherapy are mostly focusing on the process of the interactions among the participants in the group. Although those psychotherapies are also collecting data during the group processes, their approaches are mostly on the dynamic of the interactions. Gestalt therapy focuses more on the here-and-now role reversals to see one self from others' eyes. Interactional group psychotherapy emphasizes more on the here-and-now interaction among the participants using the selfreflective loop. The psychodynamic group process is more on the interpretation of defense mechanism and the core conflicts.

The proposed new method is databased focusing specifically on the facts and fantasies presented in the narrations of the group members during the group therapy sessions. Combined with the inferences from collected factual data in the narrations of participants', we observed that even though the impacts on objective measures in each modality were inconclusive, emotion awareness, metaemotion, and self-regulation actually improved compatibly in all groups.

It should be kept in mind though, that the number of the participants were small and unequal in each group. To generalize the findings of this research, larger number of participants is needed. Therefore, this study must be upscaled and applied to the real cases, if the new invented method were to be used in various settings of psychological services.

\section{Conclusion}

The working hypothesis was confirmed by data that all approaches were compatible with one to another including the invented new intervention method. The pre and post differences on all objective measures were also confirmed. Each approach facilitated specific process. Based on the visual inspection, the gain scores looked different from one approach to another. This means that each approach has specific impact on the participant's behavior.

This newly invented method using data-focused approach in the group processes can be applied with specific conditions related to factors affected the success of the intervention. At least there are three factors. The first factor is the therapist. In this study the therapist was the PI. She is a senior clinical psychologist, who has significant experiences in leading the group, and using all methods. This means that if anyone who would replicate the study, the therapist in all groups has to be experienced in using all methods.

The second factor is the client. This study involved volunteer clients who were mostly students and two junior faculty members. They were all relatively wellfunctioning people with no major psychopathology. We do not know yet whether this new approach is also effective for real clients with significant psychopathology, since the new approach was based on normal people who needed psychological service to adapt and adjust to their life problems.

The third factor is the method used. The new method invented in this study had to be studied further using a complete RCT. This way we may find the evidence that the newly invented method is effective in changing relational behavior for relatively well-functioning people who happen to have unsatisfactory personal relationship. Using the RCT design, we may find its efficacy to set the standardized procedure to be followed and we may claim how many percentage 
chances of success included specific side effects that might occur.

\section{Recommendation}

To support the evidence, upscaled study in a larger system like in public health centers is recommended. RCT design is to be used completely than using partially randomized placement for the participants like in this study. It is also suggested to simplify the procedure of the new invented method that it may be more useful to be used by other disiplines to serve the community better. Medical doctor, nurses, midwives, health caders, women activists in the community may be trained using the simplified procedure of the data-focused approach so they will be able to improve their services in public health centers.

\section{Acknowledgement}

This study will not be possible to be completed in 2011 without professor grant from the Faculty of Psychology, Universitas Gadjah Mada (UGM), Yogyakarta, Indonesia. Many thanks to our volunteer clients who diligently and genuinely presenting themselves included their psychological vulnerabilities related to their personal relationship with their significant others.

\section{References}

Barnard-Brak, L., Lan, W. Y., \& Paton, V. O. (2010). Profiles in self-regulated learning in the online learning environment. International Review of Research in Open and Distance Learning, 11(1), 61-79.

Bartsch, A., Mangold, R., Viehoff, R., \& Vorderer, P. (2006). Emotional gratifications during media use - An integrative approach. Communications,
31(3). doi: $\underline{\text { 10.1515/COMMUN.2006.018 }}$

Brackett, M. A., Mayer, J. D., \& Warner, R. M. (2004). Emotional intelligence and its relation to everyday behaviour. Personality and Individual Differences, 36(6), 1387-1402. doi: 10.1016/S01918869(03)00236-8

Brackett, M. A., Rivers, S. E., Shiffman, S., Lerner, N., \& Salovey, P. (2006). Relating emotional abilities to social functioning: A comparison of selfreport and performance measures of emotional intelligence. Journal of Personality and Social Psychology, 91(4), 780-795. doi: 10.1037/0022$\underline{3514.91 .4 .780}$

Chen, F.-C., Ku, E. C. S., Shyr, Y.-H., Chen, F.-H., \& Chou, S.-S. (2009). Job demand, emotional awareness, and job satisfaction in internships: The moderating effect of social support. Social Behavior and Personality: An International Journal, 37(10), 1429-1440. doi: $\underline{10.2224 / \mathrm{sbp} .2009 .37 .10 .1429}$

Christensen, L. B. (2007). Experimental methodology. Boston: Allyn \& Bacon.

Corsini, R. J., \& Wedding, D. (2008). Current psychotherapies (8th ed.). Belmont: Thomson Brooks/Cole.

Croyle, K. L., \& Waltz, J. (2002). Emotional awareness and couples' relationship satisfaction. Journal of Marital and Family Therapy, 28(4), 435-444. doi: 10.1111/j.1752-0606.2002.tb00368.x

Doll, B. (2010). Positive school climates. Principal Leadership, 11(4), 12-16.

Donnelly, P. J. (1992). The impact of culture on psychotherapy: Korean clients' expectations in psychotherapy. The Journal of the New York State Nurses' Association, 23(2), 12-15.

Erskine, R. G. (2010). Relational group psychotherapy: The healing of stress, 
neglect, and trauma. International Journal of Integrative Psychotherapy, 1(1), $1-10$.

Greenberg, L. S., \& Pascual-Leone, A. (2006). Emotion in psychotherapy: A practice-friendly research review. Journal of Clinical Psychology, 62(5), 611-630. doi: 10.1002/jclp.20252

Gupta, G., \& Kumar, S. (2010). Mental health in relation to emotional intelligence and self efficacy among college students. Journal of the Indian Academy of Applied Psychology, 36(1), 61-67.

Hunter, E. C., Katz, L. F., Shortt, J. W., Davis, B., Leve, C., Allen, N. B., \& Sheeber, L. B. (2011). How do I feel about feelings? Emotion socialization in families of depressed and healthy adolescents. Journal of Youth and Adolescence, 40(4), 428-441. doi: $\underline{10.1007 / \mathrm{s} 10964-010-9545-2}$

Johansson, R., Town, J. M., \& Abbass, A. (2014). Davanloo's Intensive ShortTerm Dynamic Psychotherapy in a tertiary psychotherapy service: Overall effectiveness and association between unlocking the unconscious and outcome. PeerJ, 2, e548. doi: 10.7717/ peerj.548

Lane, R. D., Sechrest, L., Riedel, R., Shapiro, D. E., \& Kaszniak, A. W. (2000). Pervasive emotion recognition deficit common to alexithymia and the repressive coping style. Psychosomatic Medicine, 62(4), 492-501. Retrieved from http://www.ncbi.nlm.nih.gov/ pubmed/10949094

Lane, R. D., \& Schwartz, G. E. (1987). Levels of emotional awareness: A cognitive-developmental theory and its application to psychopathology [published erratum appears in Am J Psychiatry, 144(4), 542]. American
Journal of Psychiatry, 144(2), 133-143. doi: 10.1176/ajp.144.2.133

Lavee, Y., \& Ben-Ari, A. (2004). Emotional expressiveness and neuroticism: Do they predict marital quality? Journal of Family Psychology, 18(4), 620-627. doi: $\underline{10.1037 / 0893-3200.18 .4 .620}$

Lilliengren, P., Johansson, R., Lindqvist, K., Mechler, J., \& Andersson, G. (2016). Efficacy of experiential dynamic therapy for psychiatric conditions: A meta-analysis of randomized controlled trials. Psychotherapy, 53(1), 90-104. doi: $10.1037 /$ pst0000024

Mitmansgruber, H., Beck, T. N., Höfer, S., \& Schüßler, G. (2009). When you don't like what you feel: Experiential avoidance, mindfulness and metaemotion in emotion regulation. Personality and Individual Differences, 46(4), 448-453. doi: $\underline{10.1016 /}$ j.paid.2008.11.013

Mitmansgruber, H., Beck, T. N., \& Schüßler, G. (2008). "Mindful helpers": Experiential avoidance, metaemotions, and emotion regulation in paramedics. Journal of Research in Personality, 42(5), 1358-1363. doi: 10.1016/j.jrp.2008.03.012

Ormrod, J. E. (2006). Educational psychology: Developing learners (5th ed.). New Jersey: Pearson Merril-Prentice Hall.

Prawitasari, J. E. (2011). Clinical psychology: Introduction to micro and macro apllications. Jakarta: Erlangga.

Rieffe, C., Oosterveld, P., Miers, A. C., Meerum Terwogt, M., \& Ly, V. (2008). Emotion awareness and internalising symptoms in children and adolescents: The Emotion Awareness Questionnaire revised. Personality and Individual Differences, 45(8), 756-761. doi: 10.1016/J.PAID.2008.08.001 
Shaughnessy, J. J., Zechmeister, E. B., \& Zechmeister, J. S. (2011). Research methods in psychology (9th ed.). New York: McGraw-Hill.

Thompson, R. J., Dizén, M., \& Berenbaum, H. (2009). The unique relations between emotional awareness and facets of affective instability. Journal of Research in Personality, 43(5), 875-879. doi: 10.1016/j.jrp.2009.07.006

Town, J. M., Abbass, A., \& Bernier, D. (2013). Effectiveness and cost effectiveness of Davanloo's intensive short-term dynamic psychotherapy:
Does unlocking the unconscious make a difference? American Journal of Psychotherapy, 67(1), 89-108.

Tseng, W. (2004). Culture and psychotherapy: Asian perspectives. Journal of Mental Health, 13(2), 151-161. doi: $\underline{10.1080 / 09638230410001669282}$

Yalom, I. D. (1985). The theory and practice of group psychotherapy. New York: BasicBooks.

Yalom, I. D. (1998). The Yalom reader: Selections from the work of a master therapist and storyteller. (B. Yalom, Ed.). New York: BasicBooks. 